\title{
Metabolic acidosis mimicking diabetic ketoacidosis after use of calorie-free mineral water
}

\author{
Berna Eren Fidanci • Erkan Sari • Ediz Yesilkaya
}

Received: 24 May 2013 / Accepted: 26 June 2013 / Published online: 12 July 2013

(C) Springer-Verlag Berlin Heidelberg 2013

To the Editor,

We have read with interest the article concerning a metabolic acidosis after use of calorie-free mineral water by Dahl et al. [2] that was recently published in your journal. Although their patient is of interest, we have a few comments regarding the diagnostic process. As it is known, the biochemical criteria for the diagnosis of diabetic ketoacidosis are hyperglycemia (blood glucose $>11 \mathrm{mmol} / \mathrm{L}[\approx 200 \mathrm{mg} / \mathrm{dL}]$ ) and venous $\mathrm{pH}<7.3$ or bicarbonate $<15 \mathrm{mmol} / \mathrm{L}$, ketonemia, and ketonuria [4]. However, the patient had only ketoacidosis and no hyperglycemia neither before nor after the diagnosis. For this reason, it is not an imitation of diabetic ketoacidosis because of the absence of the major criteria, hyperglycemia. For these reasons, it is not suitable to present the case with the title as "mimicking diabetic ketoacidosis".

Metabolic acidosis and ketosis may be the consequence of a variety of etiologies. During fasting, in response to stress, insulin secretion decreases, lipolysis and ketongenesis increase and this may lead to easily metabolic acidosis and ketosis. Development of ketoacidosis is for instance to be expected in a child who cannot eat because of herpes stomatitis due to physiologic stress combined with starvation.

Diet products are so dangerous especially for young children because they reduces food intake [1,3]. Furthermore, diet products contain cyclamates, aspartame, and acesulfame

B. E. Fidanci

School of Nursing, Gulhane Military Medical Academy,

Ankara, Turkey

E. Sari $\cdot$ E. Yesilkaya

Department of Pediatric Endocrinology, Gulhane Military Medical

Academy, Ankara, Turkey

E. Yesilkaya $(\bowtie)$

Gülhane Askeri Tıp Akademisi, Pediatrik Endokrinoloji Bilim

Dalı, 06200 Ankara, Turkey

e-mail: dredizyesilkaya@gmail.com potassium which are not suitable for the pediatric age group. These substances may be a factor reducing the appetite in a small child who cannot eat or be fed orally and has a risk of catabolic process.

Aspartame, one of the sweeteners in diet products, may be dangerous for children because it may cause metabolic acidosis. The low-calorie sweetening agent, aspartame, is degraded in the small intestine into three moieties: aspartic acid, methanol, and phenylalanine. Aspartic acid is the responsible product for the acidosis. Also methanol may lead to severe acidosis (http://rense.com/general70/aasp.htm) [5]. The use of diet products may have exacerbated the clinical symptoms in this case.

The use of diet products does not provide enough calories for children. Also it causes loss of appetite and acceleration in the development of ketoacidosis and may lead to serious complications and death. We would appreciate that the authors comment on these points.

\section{References}

1. Blundell JE, Hill AJ (1986) Paradoxical effects of an intense sweetener (aspartame) on appetite. Lancet 1:1092-1093

2. Dahl GT, Woldseth B, Lindemann R (2012) Metabolic acidosis mimicking diabetic ketoacidosis after use of calorie-free mineral water. Eur J Pediatr 171(9):1405-7

3. Dela Hunty A, Gibson S, Ashwell M (2006) A review of the effectiveness of aspartame in helping with weight control. Nutr Bull 31:115-128

4. Dunger DB, Sperling MA, Acerini CL, Bohn DJ, Daneman D, Danne TP, Glaser NS, Hanas R, Hintz RL, Levitsky LL, Savage MO, Tasker RC, Wolfsdorf JI (2004) ESPE; LWPES. ESPE/LWPES consensus statement on diabetic ketoacidosis in children and adolescents. Arch Dis Child 89(2):188-94

5. Martini B. Report for schools, ob-gyn and pediatricians on children and aspartame/MSG, report on aspartame and children, http://www. wnho.net/report_on_aspartame_and_children 